\title{
Article
}

\section{Designing a Cleavable Cell Surface Protein for Cytotherapy and Drug Delivery Applications}

\author{
Matthew T. Basel ${ }^{1, *}$, Tej B. Shrestha ${ }^{1,2}$, Marla Pyle ${ }^{1}$, Tuyen Duong Thanh Nguyen ${ }^{2,3}$, Santosh Aryal ${ }^{2,3}$, Deryl \\ L. Troyer ${ }^{1}$ and Stefan H. Bossmann ${ }^{3,4, * \text { (D) }}$ \\ 1 Department of Anatomy and Physiology, College of Veterinary Medicine, Kansas State University, Manhattan, \\ KS 66506, USA; tbs3@vet.k-state.edu (T.B.S.); mpyle@vet.k-state.edu (M.P.); troyer@vet.k-state.edu (D.L.T.) \\ 2 Nanotechnology Innovation Center of Kansas State (NICKS), Kansas State University, Manhattan, \\ KS 66506, USA; tuyennguyen@ksu.edu (T.D.T.N.); saryal@ksu.edu (S.A.) \\ 3 Department of Chemistry, Kansas State University, Manhattan, KS 66506, USA \\ 4 Department of Cancer Biology, The University of Kansas Medical Center and University of Kansas Cancer \\ Center, Kansas, KS 66160, USA \\ * Correspondence: mbasel@vet.k-state.edu (M.T.B.); sbossmann@kumc.edu (S.H.B.); \\ Tel.: +1-785-477-7135 (S.H.B.)
}

Featured Application: A synthetic gene that codes for a protein comprised of a streptavidin domain for binding biotin-labeled cargo, a urokinase cleavage domain for release by urokinase plasminogen activator, and a PLAP domain for cell-surface expression enables effective cellbased delivery of small molecules and nanostructures to tumors.

check for

updates

Citation: Basel, M.T.; Shrestha, T.B.; Pyle, M.; Nguyen, T.D.T.; Aryal, S.; Troyer, D.L.; Bossmann, S.H.

Designing a Cleavable Cell Surface Protein for Cytotherapy and Drug Delivery Applications. Appl. Sci. 2021, 11, 2792. https://doi.org/10.3390/ app11062792

Academic Editor: Hidenori Otsuka

Received: 5 March 2021

Accepted: 17 March 2021

Published: 21 March 2021

Publisher's Note: MDPI stays neutral with regard to jurisdictional claims in published maps and institutional affiliations.

Copyright: (c) 2021 by the authors. Licensee MDPI, Basel, Switzerland. This article is an open access article distributed under the terms and conditions of the Creative Commons Attribution (CC BY) license (https:// creativecommons.org/licenses/by/ $4.0 /)$.

\begin{abstract}
Many cytotherapy applications focus on delivering a therapeutic molecule or nanoparticle to a disease site. One challenging step in this delivery is releasing the therapeutic molecule from the delivery cell upon arrival at the delivery sight. Here a protein is designed and expressed that can bind a biotin-labeled cargo and release that cargo in response to the presence of urokinase plasminogen activator. A gene was designed that coded for a protein that contained a streptavidin domain for binding biotin-labeled cargo, a urokinase cleavage domain for release by urokinase plasminogen activator, and a PLAP domain for cell-surface expression. The utility of the resultant protein was tested with biotin (5-fluorescein) and a biotinylated PLGA nanoparticle to test the performance of the delivery systems with models for small molecule drugs and nanoformulations. When expressed in neural progenitor cells (C17.2), the designed protein was able to bind both the biotin (5-fluorescein) and the biotinylated PLGA nanoparticles and was able to release the biotin (5-fluorescein) in response to urokinase plasminogen activator. This designed, multi-domain protein may prove useful as a method for specifically releasing a cargo from delivery cells at a target site.
\end{abstract}

Keywords: synthetic biology; cytotherapy; PLGA nanoparticles; streptavidin-biotin

\section{Introduction}

Cytotherapy, using cells to treat or to deliver treatment to a disease, is a growing field of research in many areas, including cancer and neural disease [1,2]. Cytotherapy can be particularly effective because of the unique properties of certain cells to actively infiltrate the diseased site. While some cytotherapies rely solely on the properties of the treatment cell $[3,4]$, many cytotherapies use cells as targeting agents to actively deliver an exogenous payload to the abnormal tissue [5-8]. One persistent challenge in these delivery-oriented cytotherapies is determining how to release or use the payload at the disease site.

One potential method for releasing the cytotherapy payload would be to attach it to the delivery cell with a cleavable linker. Elevated protease levels are a hallmark of several disease states [9-11]. For example, in many cancers the matrix-metalloproteinases and/or urokinase plasminogen activator (uPA) are highly upregulated [12-16]. uPA is a part of 
the plasmin system and cleaves the inactive plasminogen into active plasmin which has cascade effects modifying the extracellular matrix, vascular development, and growth factor availability. uPA also cleaves its cell-surface receptor, the urokinase plasminogen activator receptor (uPAR). A consensus sequence for uPA has been identified [17,18], SGRSA, that has been used for a variety of medicinal applications [18,19]. If a payload was connected to a delivery cell with a linker that was cleavable by uPA the payload would remain attached to the delivery cell until it reached an area with high uPA activity at which point it would be released.

Streptavidin [20] is a well-known bacterial protein that binds biotin with high affinity. This binding affinity makes streptavidin an attractive possibility for engineering a protein that would attach a biotin-labeled payload to the surface of a cell. Unfortunately, while streptavidin binds biotin in a 1:1 ratio, the actual binding event occurs between four molecules of streptavidin cooperatively binding four molecules of biotin. This 4:4 correspondence creates challenges for successfully engineering a hybrid protein containing a streptavidin domain. Recently, a modified streptavidin protein has been engineered that acts as monomer, binding biotin on a 1:1 basis (referred to as mono-streptavidin, mSA) [21,22]. This expands its potential for engineering into a designed protein as a biotin binding moiety.

Placental alkaline phosphatase (PLAP) [23] is a membrane anchored protein that is used as a model to understand phosphatidylinositol-glycan (GPI) anchored proteins. A sequence (PLAP domain) has been identified at the C-terminal end of the PLAP protein which signals the attachment of the protein to the GPI anchor and expression on the surface of the cell. This domain has been engineered into other proteins to cause their cell surface expression through GPI anchors [23].

Here, a cleavable mono-streptavidin (cmSA) delivery protein is designed and tested that incorporates an mSA domain for binding biotin-labeled payloads, a uPA cleavage domain for efficient release, and a PLAP domain for cell surface anchoring (Figure 1). This protein could be one method for attaching and delivering a payload using cytotherapy.

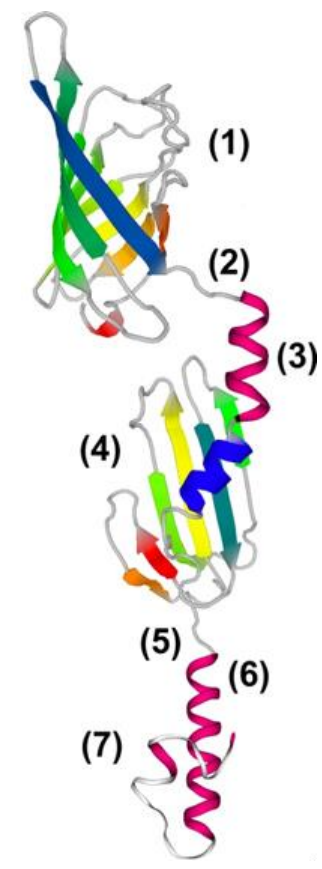

Figure 1. Schematic of the designed fusion protein containing seven components: (1) a streptavidin/rhizavidin hybrid peptide; (2) the uPA consensus sequence (SGRSA); (3) an alpha helix spacer $[\mathrm{EAAK}]_{3}$; (4) the uPA binding domain of UPAR; (5) a FLAG tag for antibody recognition; (6) a HIS tag for isolation and identification; and (7) a PLAP sequence for GPI binding and anchoring to the membrane. 


\section{Materials and Methods}

\subsection{Materials}

General chemicals were from Sigma-Aldrich, St. Louis, MO. SOC medium was from Clontech, LB agar was from Invitrogen (Carlsbad, CA), and ampicillin was from SigmaAldrich (St. Louis, MO, USA).

1,2-distearoyl-sn-glycero-3-phosphoethanolamine- $\mathrm{N}$-[biotinyl(polyethylene glycol)2000] (ammonium salt) (DSPE-PEG-Biotin), 1,2-distearoyl-sn-glycero-3-phospho-(1'-racglycerol) (sodium salt) (DSPG), L- $\alpha$-Phosphatidylethanolamine-N-(lissamine rhodamine B sulfonyl) (Ammonium Salt) (Egg Transphosphatidylated, Chicken) (RhB-PE), and 1,2distearoyl-sn-glycero-3-phosphoethanolamine-N-[succinyl(polyethylene glycol)- 2000] (ammonium salt) (DSPE-PEG-succ) were purchased from Avanti lipid (Alabaster, AL, USA). 50:50 Poly(D,L-lactide-co-glycolide) ester terminated (PLGA-ester) $(0.55-0.75 \mathrm{dL} / \mathrm{g})$ was purchased from DURECT Corporation (Birmingham, AL, USA)

\subsection{Plasmid Design}

A cleavable mono-streptavidin gene ( $\mathrm{cmSA}$ ) with the following sequence was ordered from GenScript (Piscataway, NJ, USA) as an insert in the pQCXIP plasmid (Clontech, Mountain View, CA, USA):

\begin{tabular}{|c|c|c|c|}
\hline & & & \\
\hline CTGTCTCTGG & CACTGGTCAC & АACTCTGCC & ATGGGAGCTG \\
\hline AGGCAGGAAT & TACCGGAACT & GGTACAATC & AGCACGGTTC \\
\hline АстTтTAст & GTAACCGCTG & AGCCGATGG & CAATTTGACC \\
\hline GGCAATACG & AGAACCGAGC & CAGGGCACC & \\
\hline СТСАСССТА & CACGCTGACA & GTAGATATA & CGGGA \\
\hline CTGGAGTGG & CGGGTTGAGT & GAACAATTC & АCTGAAA \\
\hline ГGCCACAGCA & GGACAGAATG & GCGCGGTCAA & ACCAAC $\triangle A$ \\
\hline CGCTGAGGC & TAGAATTAAC & ACCCAATGGA & $\cos +4$ \\
\hline GAGGGCGGA & AGCGGCCCAG & TACGGAGCA & $\mathrm{GGC}$ \\
\hline CATTTACGA & AAGTAAAACC & ATCAGCAGCT & TCAGGTA \\
\hline ACTATAAAGA & TGACGACGAT & AAGGAAGCGG & CAGCAAAAGA \\
\hline GCTGCGGCG & AAAGAGGCCG & CCGCAAAAAG & GGCC \\
\hline GCGGAAGCGG & CAGCAAAAGA & AGCTGCGGCG & AAAGA \\
\hline CCGCAAAACT & TAGGTGTATG & CAATGCAAGA & CAAATGGCG \\
\hline TTGCCGCGTA & GAGGAGTGCG & CGCTTGGCCA & AGACCTTTGC \\
\hline AGGACCACCA & TTGTTAGGCT & CTGGGAAGAG & GGAGAGGAAC \\
\hline ACTCGT & CGAGAAAAGC & TGTACACACT & CAGAGAAAA \\
\hline TAATCGCACA & CTCAGCTATC & GGACCGGGTT & AAAGATCACT \\
\hline TCCCTGACAG & AAGTCGTCTG & CGGGCTCGAT & TTATGTAACC \\
\hline AAGGAAACAG & CGGAAGAGCT & GTTACTTATT & CCAGATCACG \\
\hline I'A'AAGCAC & CATCACCA & ATCATCACCA & CCATCACACC \\
\hline ACTGATGCTG & CCCATCCTGG & AAGGTCTGTG & GTGCCTGCCT \\
\hline TGCTGCCTCT & GCTGGCTGGC & ACTCTGCTGC & TGCTGGAGA \\
\hline & & & \\
\hline
\end{tabular}

This corresponds to an expressed protein with the following sequence: 


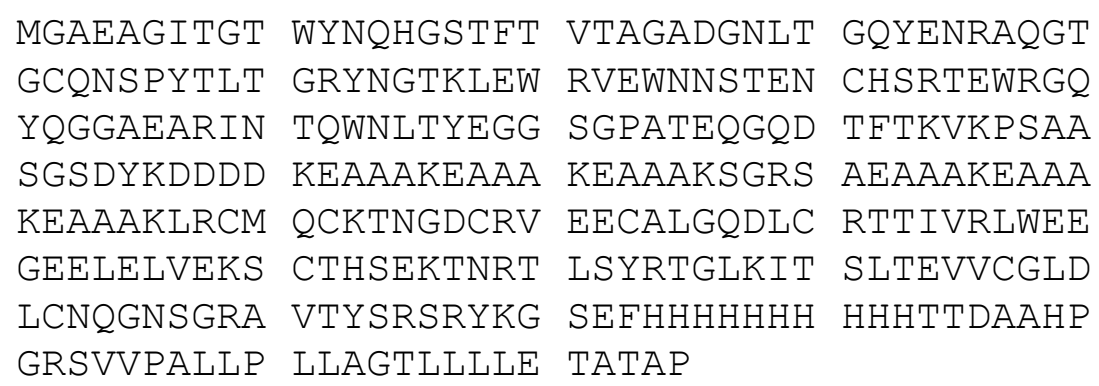

Amino acid residues 1-123 correspond to a published sequence for an engineered streptavidin designed to bind biotin on a 1:1 basis as opposed to a 4:4 basis [21,22]. Residues 124-131 are a flag tag. Residues 132-166 correspond to a cleavage sequence (SGRSA) for urokinase plasminogen activator (uPA) flanked by two rigid alpha helix spacers designed to separate protein domains and allow protease access [24]. Residues 167-263 correspond to the urokinase plasminogen activator receptor (UPAR) cleavage domain. Residues $264-273$ are a histidine tag. Residues 274-305 correspond to a PLAP sequence which signals the connection of a GPI anchor.

\subsection{Plasmid Expansion}

Upon receipt of the plasmid from GenScript, the plasmid was expanded using Stellar Competent Cells (Clontech) according to specified directions. Briefly, $5 \mathrm{ng}$ of plasmid DNA was added to $50 \mu \mathrm{L}$ of cells on ice and incubated for $30 \mathrm{~min}$. The cells were heat shocked at $42{ }^{\circ} \mathrm{C}$ for $5 \mathrm{~min}$ and then returned to ice bath for $2 \mathrm{~min}$. About $450 \mathrm{uL} \mathrm{SOC}$ medium was then added and incubated at $37^{\circ} \mathrm{C}$ for $1 \mathrm{~h}$. Transformed bacteria were selected by plating on an ampicillin plate and incubating overnight at $37^{\circ} \mathrm{C}$. After incubation, positive colonies were isolated from the agar plate and cultured in LB medium with ampicillin.

\section{4. $P C R$}

To verify plasmid expansion, DNA was isolated from a $100 \mathrm{~mL}$ culture of transformed bacteria using the Qiagen Maxi Kit (Qiagen, Germantown, MD, USA) according to specified directions. DNA purity and concentration were determined using a NanoDrop ND8000 (Thermo Fisher Scientific, Waltham, MA, USA). Two primer sets specific for the monostreptavidin gene that produced 200bp PCR products were designed and purchased from IDT (Coralville, IA, USA):

\section{Primer 1f: AGCAACAGAACAGGGACAGG \\ Primer 1r: TGCATGCACCTCAGTTTAGC \\ Primer 2f: GAGCTGGTCGAAAAGTCCTG \\ Primer 2r: GGCTGCATCGGTAGTATGGT}

A PCR reaction was set up as follows: 1 cycle of $95^{\circ} \mathrm{C}$ for $5 \mathrm{~min}, 30$ cycles of $95^{\circ} \mathrm{C}$ for $30 \mathrm{~s}, 60^{\circ} \mathrm{C}$ for $30 \mathrm{~s}, 72^{\circ} \mathrm{C}$ for $45 \mathrm{~s}$. Following PCR, product was analyzed by running on a $2 \%$ agarose gel along with a GeneRuler $1 \mathrm{~kb}$ DNA ladder (Fisher, Hampton, NH). PCR performed with both primer sets returned the expected $200 \mathrm{bp}$ product, indicating the presence of the cmSA gene (Figure 2A). 
A

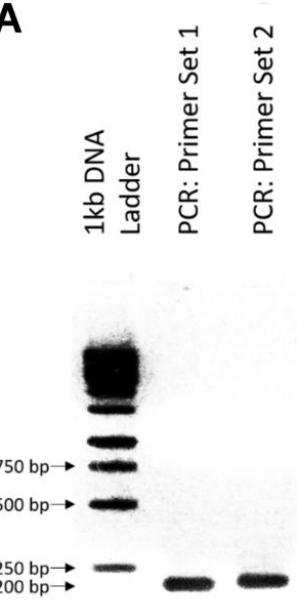

B

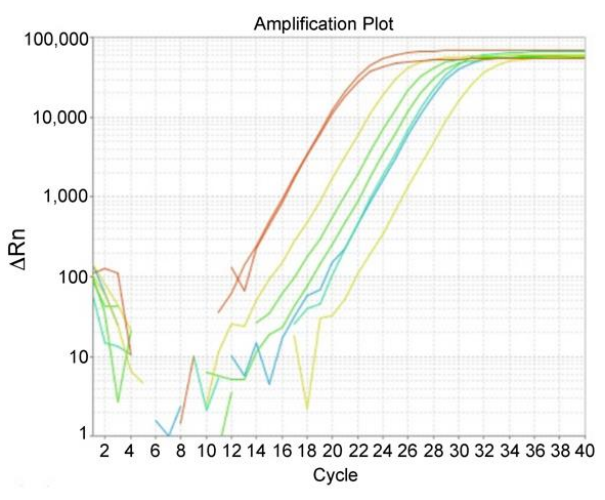

C

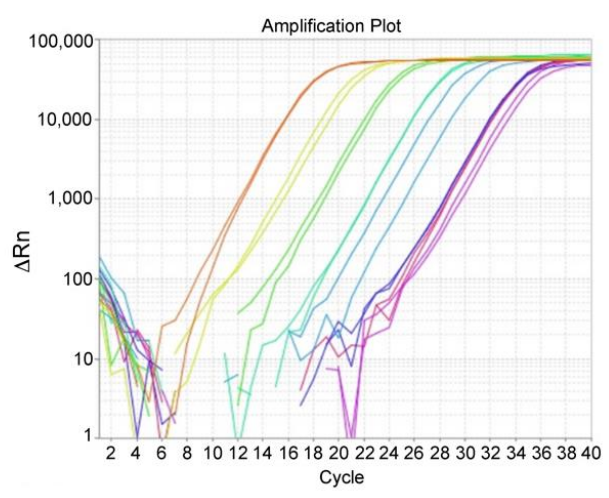

Figure 2. Production of viral particles. (A) PCR products post-amplification run on a $2 \%$ agarose gel. Both primer sets returned the expected 200 bp product. $($ B $)$ qPCR sample results. Red: $1 \times$ sample, Yellow: $0.1 \times$ sample, Green: $0.01 \times$ sample, Blue: $0.001 \times$ sample. $(C)$ qPCR standard curve. Red: $5 \times 10^{7}$ copies, Yellow: $5 \times 10^{6}$ copies, Green: $5 \times 10^{5}$ copies, Teal: $5 \times 10^{4}$ copies, Blue: $5 \times 10^{3}$ copies: Dark Blue/Purple: negative control.

\subsection{Viral Particle Production}

GP2-293 cells (Clontech) were transfected using the Retro-X universal packaging system (Clontech) according to the manufacturer's directions. Briefly, 4.5e6 GP2-293 cells were plated in a 100-mm culture dish in a medium containing DMEM, 10\% FBS (SigmaAldrich). The next day, $15 \mu \mathrm{g}$ of both the cmSA pQCXIP plasmid and the Retro-X envelope plasmid were diluted to $600 \mathrm{uL}$ in Xfect reaction buffer and $9 \mu \mathrm{L}$ of Xfect polymer was added. The solution was incubated for $10 \mathrm{~min}$ and then added dropwise to the GP2-293 cells. The cells were incubated with the plasmids for $8 \mathrm{~h}$, then the medium was removed, and fresh medium was added.

Transfected GP293 were cultured for $48 \mathrm{~h}$ and then the media was harvested and centrifuged at $500 \times g$ for $10 \mathrm{~min}$ and the supernatant was added to three volumes of the Retro- $X$ concentrator solution. The viral concentrator was incubated at $4{ }^{\circ} \mathrm{C}$ overnight and then the viral particles were harvested by centrifuging at $1500 \times \mathrm{g}$ for $45 \mathrm{~min}$ at $4{ }^{\circ} \mathrm{C}$. The supernatant was discarded, and the viral particles were resuspended in $1 \mathrm{~mL}$ PBS. The virus was aliquoted in to $150 \mu \mathrm{L}$ aliquots and stored at $-80^{\circ} \mathrm{C}$ until needed.

To determine viral titer, RNA was isolated from 1 aliquot $(150 \mu \mathrm{L})$ of viral particles using the Nucleospin virus purification kit (Clontech) according to directions. qRT-PCR was performed using the Retro-X qRT-PCR Titration Kit (Clontech) according to directions. Analysis of the amplification showed $5 \mathrm{e} 6$ relative copies of the virus which corresponded to $1.7 \times 10^{9}$ viral particles $/ \mathrm{mL}$ (Figure $2 \mathrm{~B}, \mathrm{C}$ ).

\subsection{Transduction}

C17.2 neural progenitor cells were a gift from V. Ourednik (Iowa State University, Ames, IA, USA); this cell line was originally developed in Evan Snyder's lab at Harvard University (Boston, MA, USA) [25]. C17.2 cells were plated at 9e4 cells/well in a six well plate in medium containing DMEM, 10\% FBS, 5\% horse serum (Gibco, Gaithersburg, MD, USA), and $4 \mathrm{mM}$ glutamine. The next day, $4 \mu \mathrm{g} / \mathrm{mL}$ polybrene was added to the medium and then $96 \mu \mathrm{L}$ (180 viral equivalents) of viral particle concentrate was added dropwise to the medium. Cells were cultured overnight and then the medium was removed and replaced with medium containing $3 \mu \mathrm{g} / \mathrm{mL}$ puromycin (Invivogen, San Diego, CA, USA). Medium was removed and replaced daily for 4 days. Once cells reached confluency, they were lifted and plated in a T75 flask. Once the T75 reached confluency, cells were lifted, and stocks were frozen. Cells were maintained in $3 \mu \mathrm{g} / \mathrm{mL}$ puromycin and labeled as cmSA-C17.2. 


\subsection{Fluorescein Labeling}

To demonstrate the presence of the cmSA gene product on the surface of the C17.2 cells, cells were incubated with biotin (5-fluorescein) (Sigma-Aldrich) as follows. cmSAC17.2 or control C17.2 cells were plated in a six-well plate so as to be $70 \%$ confluent the next day. The next day media was removed from all wells and replaced with media containing $10 \mu \mathrm{g} / \mathrm{mL}$ biotin (5-fluorescein). Cells were incubated for $30 \mathrm{~min}$ and then washed $3 \times$ with PBS. Cells were fixed in buffered neutral formalin (BNF; Sigma-Aldrich) and fluorescence was visualized using the FITC filter on a Zeis Axiovert (Zeiss USA, Thornwood, NY, USA) and images were captured using a ProgRes C3 camera (Jenoptik, Jena, Germany).

\subsection{Nanoparticle Synthesis}

Biotin functionalized polymeric nanoparticles were prepared through a solvent displacement method. In brief, $100 \mu \mathrm{g}$ DSPG, $260 \mu \mathrm{g}$ DSPE-PEG-succ, $100 \mu \mathrm{g}$ DSPE-PEG-Biotin, and $10 \mu \mathrm{g}$ RhB-PE were dispersed in $2 \mathrm{~mL}$ water containing $4 \%$ ethanol (v/v). The lipid suspension was stirred at $60^{\circ} \mathrm{C}$ for $30 \mathrm{~min}$ until the cloudy solution turned clear. To this solution, $400 \mu \mathrm{L}$ of $1 \mathrm{mg}$ PLGA-ester in acetonitrile was added dropwise followed by the addition of $1 \mathrm{~mL}$ Milli-Q water. The mixture was stirred continuously for additional $1 \mathrm{~h}$ at room temperature to evaporate the organic solvent. The nanoparticles were further purified using Amicon Ultra-4 centrifugal filter (Millipore, MA) with a molecular weight cut-off of $10 \mathrm{kDA}$ and stored at $4{ }^{\circ} \mathrm{C}$ for further use.

\subsection{Nanoparticle Characterization}

The hydrodynamic size and zeta potential measurements of the prepared nanoparticles were analyzed by dynamic light scattering (DLS) using a Zeta sizer Nano ZSP (Malvern, Worcestershire, UK) (Figure 3A). The Smoluchowski model was used to calculate the zeta potential value (Figure 3B). All data represent the average OF triplicate measurements of samples prepared in different preparations. The morphology of the prepared BNP was further analyzed using transmission electron microscope (TEM, Tecnia G2, Spirit Bio TWIN, Los Angeles, CA, USA). TEM sample was prepared by drop casting and evaporation technique using a fomvar-coated copper grid (400 mesh). TEM images were analyzed by GATAN digital imaging system (GATAN, Inc., Pleasanton, CA, USA) (Figure 3D).

A

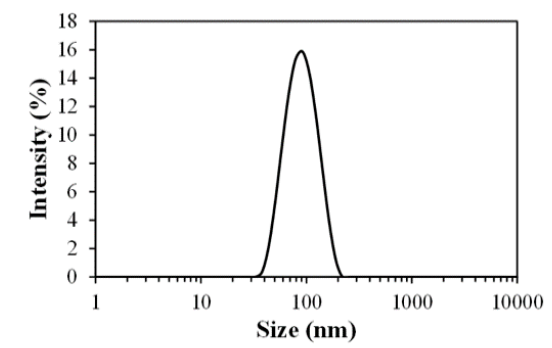

C

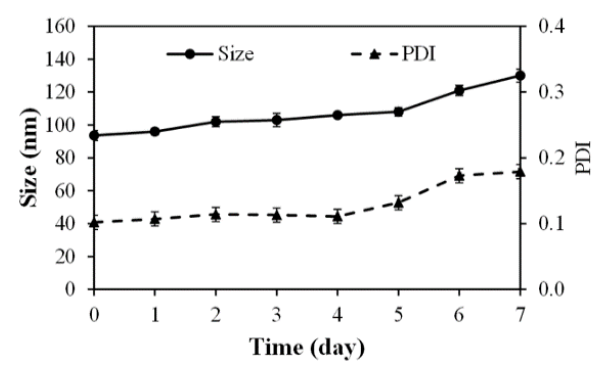

B

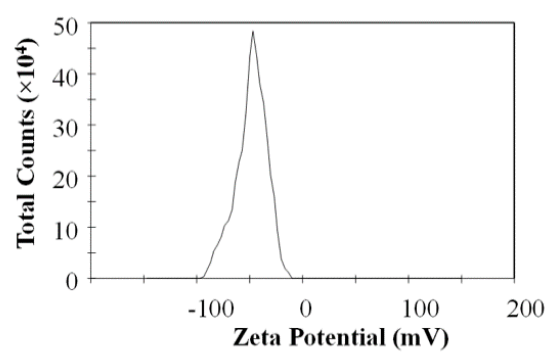

D

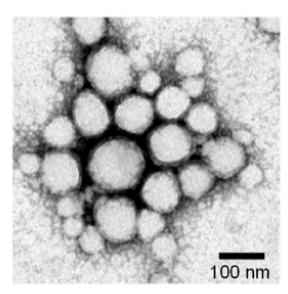

Figure 3. Physicochemical characterization of biotin functionalized polymeric nanoparticles. (A) Hydrodynamic size of PLGA nanoparticles showing Z-average of $95 \pm 5 \mathrm{~nm}$. (B) Zeta potential of PLGA nanoparticles demonstrates the negative charge property of PLGA nanoparticles. (C) A stability of PLGA nanoparticles in ionic condition (pH 7.4). (D) Representative TEM image of PLGA nanoparticles with core-shell structure. 
The stability of the nanoparticles in physiological ionic condition was investigated at pH 7.4 using PBS. In brief, $500 \mu \mathrm{L}$ of $1 \mathrm{mg} / \mathrm{mL}$ nanoparticles in PBS and incubated at $37^{\circ} \mathrm{C}$ with rotating motion for 7 days. The stability of nanoparticles was determined by measuring the particle size and PDI every $24 \mathrm{~h}$ for 7 days using DLS (Figure 3C).

\subsection{Nanoparticle Labeling}

To determine if the cmSA gene could bind to biotin-labeled nanoparticles, C17.2 cells were incubated with the PLGA-rhodamine-biotin nanoparticles as follows. cmSA-C17.2 or control C17.2 cells were plated in a six-well plate so as to be $70 \%$ confluent the next day. The next day media was removed from all cells and replaced with media containing $180 \mu \mathrm{g} / \mathrm{mL}$ PLGA-rhodamine-biotin nanoparticles. Cells were incubated for $30 \mathrm{~min}$ and then washed $3 \times$ with PBS. Cells were fixed in BNF and fluorescence was visualized using the TRITC filter on a Zeis Axiovert (Zeiss USA, Thornwood, NY, USA) and images were captured using a ProgRes C3 camera (Jenoptik, Jena, Germany).

\subsection{Urokinase Assay}

To demonstrate the ability of uPA to cleave the cmSA protein and release the cargo, cmSA-C17.2 were incubated with biotin (5-fluorescein) and then uPA (R \& D Systems, Minneapolis, MN, USA) as follows. cmSA-C17.2 were plated in a forty-eight-well plate so as to be $70 \%$ confluent the next day. The next day, the medium was removed and replaced with medium containing $10 \mu \mathrm{g} / \mathrm{mL}$ biotin (5-fluorescein). Cells were incubated for $20 \mathrm{~min}$ and then the medium was removed and washed $3 \times$ with Krebs-Ringer. Total of $50 \mathrm{IU} / \mu \mathrm{L}$ uPA in Krebs-Ringer buffer was added to one half of the wells (24 wells), and Krebs-Ringer buffer (no uPA) was added to the other half of the wells (24 wells) as control. Wells were incubated at $37^{\circ} \mathrm{C}$ and medium was removed from 3 wells of uPA sample and 3 wells of control at $0,5,10,15,20,25,30$, and 45 min and placed in a black 96-well plate suitable for fluorescence. Fluorescence in the medium was measured using an IVIS ${ }^{\text {TM }}$ Live Imager (Caliper, Waltham, MA, USA).

\subsection{Confocal Microscopy}

cmSA-C17.2 cells were plated on glass coverslips. Cells were then incubated for $10 \mathrm{~min}$ in either $10 \mu \mathrm{g} / \mathrm{mL}$ biotin (5-fluorescein) or for $1 \mathrm{~h}$ in $200 \mu \mathrm{g} / \mathrm{mL}$ PLGA-rhodamine-biotin. Cells were then washed $3 \times$ in PBS and then fixed in $10 \%$ BNF. After fixing cells, nuclei were counter stained by incubating for $10 \mathrm{~min}$ in $5 \mu \mathrm{g} / \mathrm{mL}$ Hoechst. Cells were then washed with $3 \times$ in PBS. All samples were kept in $1 \times \mathrm{PBS}$ and stored at $4{ }^{\circ} \mathrm{C}$ in dark until confocal microscopy. Finally, cells were imaged by confocal microscopy (LSM 700, Carl Zeiss, Göttingen, Germany).

\section{Results}

\section{1. cmSA Expression and Function}

To demonstrate the expression and function of the cmSA gene, C17.2 neural progenitor cells were transduced with cmSA-pQCXIP, and positive clones were selected with puromycin. Once a stable cell line had been produced, cmSA-C17.2 and C17.2 were incubated for $30 \mathrm{~min}$ in $10 \mu \mathrm{g} / \mathrm{mL}$ biotin (5-fluorescein), washed and fixed. Fluorescence microscopy showed significant fluorescence in the cmSA-C17.2 but not the control C17.2 (Figure 4A,B) demonstrating the expression of the cmSA gene and the ability of the monostreptavidin domain to bind biotin. Similarly, cmSA-C17.2 and C17.2 were incubated for 30 $\mathrm{min}$ in $180 \mu \mathrm{g} / \mathrm{mL}$ PLGA-rhodamine-biotin nanoparticles, washed and fixed. Fluorescence microscopy showed significant fluorescence in the cmSA-C17.2 but not the control C17.2 (Figure 4C,D). 


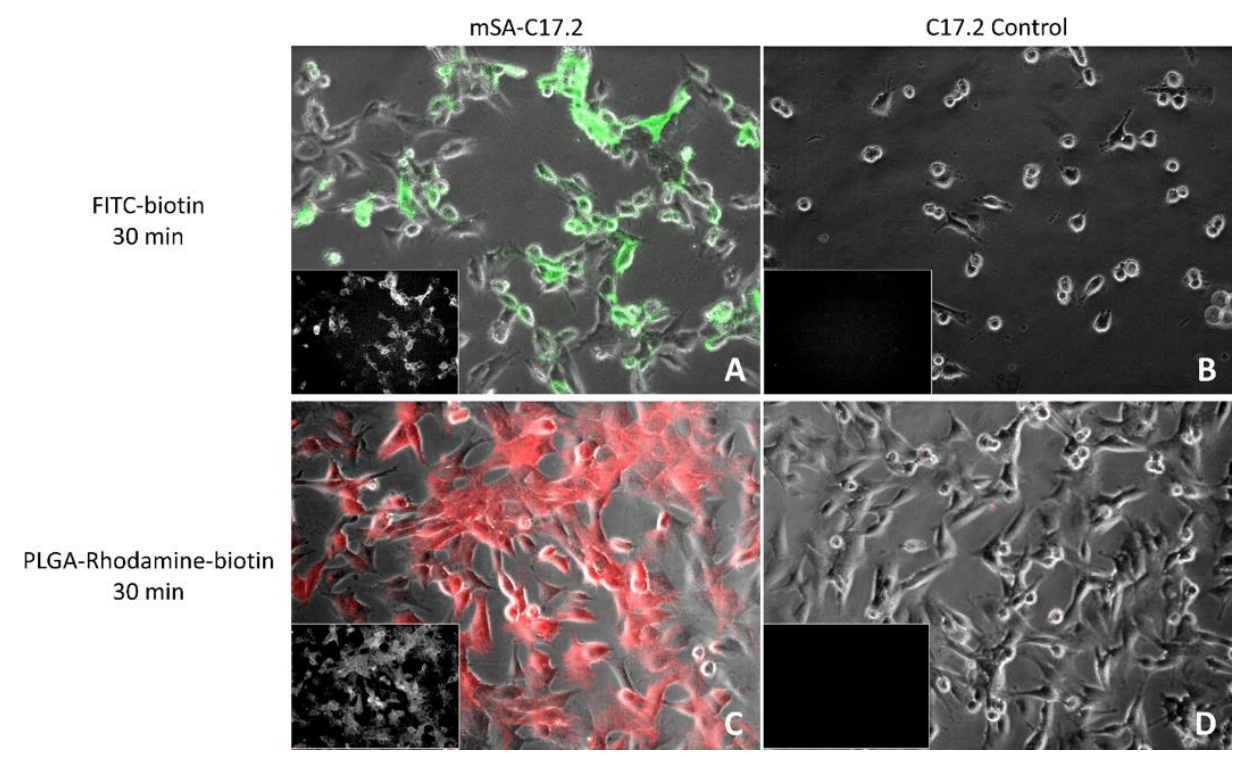

Figure 4. The cmSA protein can bind small molecules or nanoparticles containing biotin. (A): cmSAC17.2 labeled with biotin (5-fluorescein); (B): C17.2 labeled with biotin (5-fluorescein); (C): cmSAC17.2 labeled with PLGA-rhodamine-biotin; (D): C17.2 labeled with PLGA-rhodamine-biotin. Green $=$ fluorescein fluorescence. Red $=$ rhodamine fluorescence. Insets: A/B: fluorescein fluorescence without bright field overlay. C/D: rhodamine fluorescence without bright field overlay.

\section{2. cmSA Cleavage by $u P A$}

To demonstrate the ability of cmSA to be cleaved by uPA, cmSA-C17.2 cells were incubated for $30 \mathrm{~min}$ in $10 \mu \mathrm{g} / \mathrm{mL}$ biotin (5-fluorescein) and washed thoroughly. Cells were then incubated with or without uPA and medium was removed at 5-min intervals to determine the amount of fluorescein released. Data showed significant release of fluorescein fluorescence within $45 \mathrm{~min}$ from the uPA treated cells and minimal release of fluorescence from the control cells (Figure 5, $p=0.0014$ ) showing that $\mathrm{uPA}$ is able to cleave the cmSA protein and release the $\mathrm{N}$-terminal domain into the media.
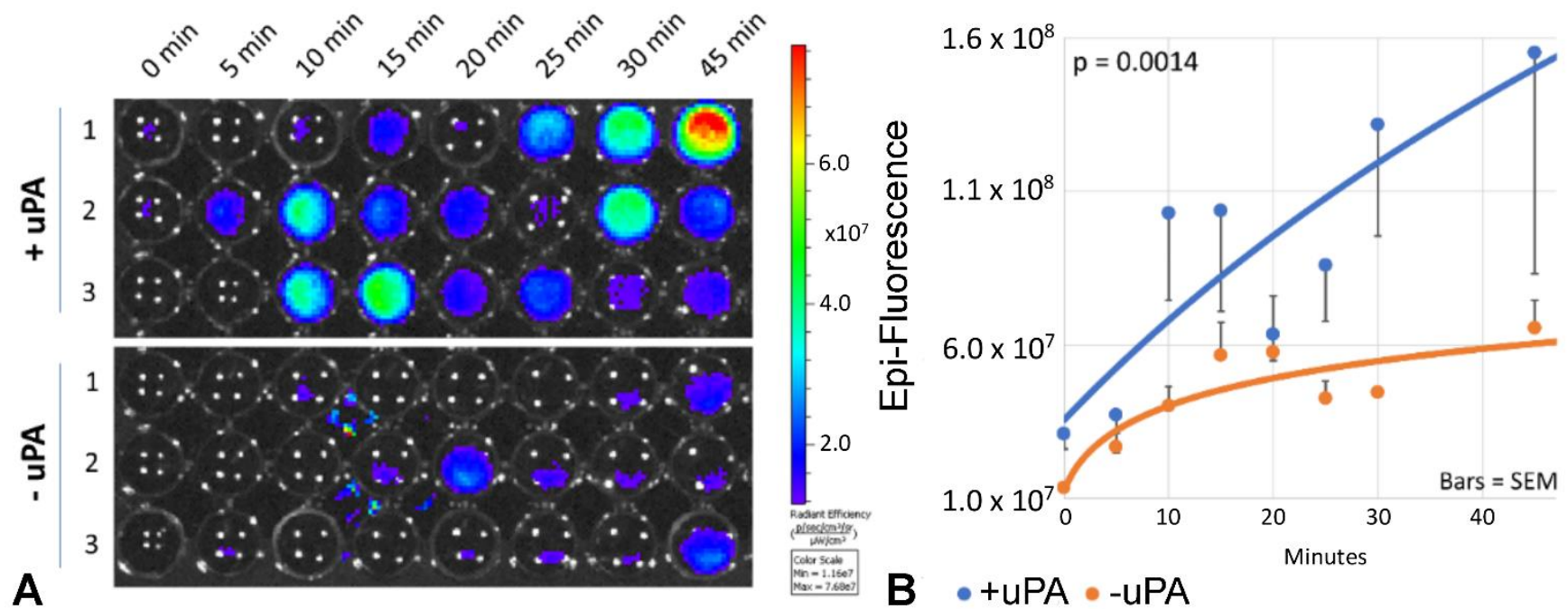

Figure 5. Urokinase can cleave the cmSA protein. (A): IVIS ${ }^{\mathrm{TM}}$ images of media harvested from biotin (5-fluorescein) labeled cmSA-C17.2 incubated with or without uPA. (B): Numerical data from panel A with best fit curves to demonstrate the trends. The repeated measures statistical test demonstrated the difference between uPA and no uPA was highly significant $(p=0.0014)$. 


\subsection{Confocal Microscopy}

To better determine the cellular location of the bound biotin (5-fluorescein) and PLGArhodamine-biotin nanoparticles, cmSA-C17.2 cells were plated on a glass cover slip and incubated for $10 \mathrm{~min}$ in either $10 \mu \mathrm{g} / \mathrm{mL}$ biotin (5-fluorescein) or $200 \mu \mathrm{g} / \mathrm{mL}$ PLGArhodamine-biotin, washed, incubated in medium for $1 \mathrm{~h}$ and then fixed. Confocal images of the biotin (5-fluorescein)-labeled cells showed markedly increased fluorescence on the margins of the cells, suggesting that the small molecule was retained on the membrane (Figure 6A). In contrast, the nanoparticle, PLGA-rhodamine-biotin, showed punctate staining throughout the cytoplasm, suggesting that the nanoparticle was bound to the surface and then internalized (Figure 6B).

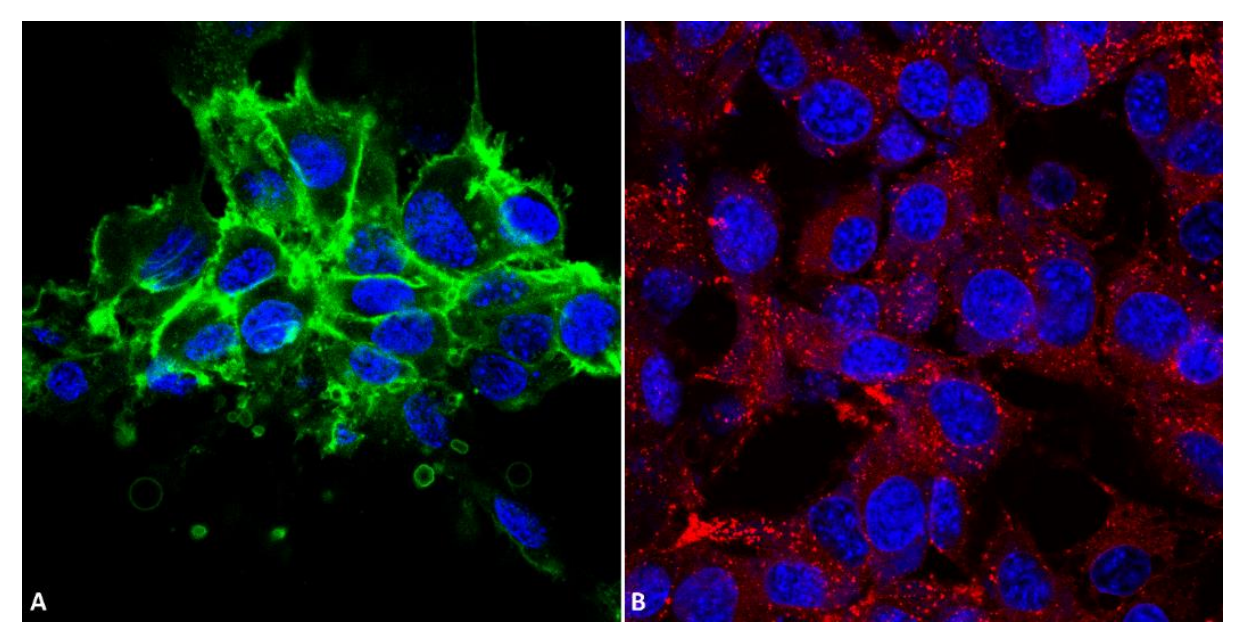

Figure 6. Confocal images of labeled cmSA-C17.2. (A): cmSA-C17.2 labeled with biotin (5-fluorescein). (B): cmSA-C17.2 labeled with PLGA-rhodamine-biotin nanoparticles.

\section{Discussion}

De-novo design of proteins with novel functions is an extremely complex computational technique. A potentially simpler method is fusion protein design which uses naturally occurring protein domains in novel combinations to design new functions [26]. This method has been used to design a wide array of synthetic proteins with novel combinations of functions $[24,26,27]$. Here, this method was used to combine the substrate binding function of a novel monostreptavidin protein with the ability of uPAR to be cleaved by uPA in order to design a system that could release a payload in response to uPA activity. The fusion protein method allowed the design of a protein that could: (1) bind biotinylated cargo; (2) be expressed on the cell surface; and (3) release the cargo in response to uPA activity by using previously designed or naturally occurring domains from other proteins. This facilitated the design of a novel protein with novel activity with significantly less input than de-novo methods.

One challenge in fusion protein design is designing peptide linkers between the domains that allow each domain to fold correctly and interact as expected [24]. Placing protein domains next to each other in a fusion protein runs the risk of having the domains interact in unexpected ways leading to a misfolded and/or inactive protein. To reduce the chance of this, in the protein designed here, relatively rigid $\alpha$-helix spacers were used to insulate the domains from each other and to allow uPA access to the cleavage sequence.

In the expressed mSA protein, each domain functioned as expected. The PLAP sequence caused the mSA protein to be expressed on the cell surface (Figure 6). The modified mono-streptavidin domain was able to efficiently bind biotinylated moieties (Figure 4). The uPA consensus sequence and uPAR domain was able to be cleaved by uPA (Figure 5) allowing release of the payload.

The purpose in designing this protein was to allow a payload to be loaded onto the surface of tumor-homing cells and then be released in the elevated uPA activity often found 
in tumors. The biotinylated fluorescein was an example of a small-molecule drug-like molecule. This system could be used to target small-molecule chemotherapies (e.g., doxorubicin, cisplatin, vincristine, etc.,) to uPA producing tumors using modified tumor-tropic delivery cells. This system could allow for a simple method for loading delivery cells with a therapeutic and then releasing that therapeutic at the target location.

One unexpected result in the system was the internalization of nanoparticles bound to the cmSA protein. C17.2 cells are not known to be significantly phagocytic, nor, as neural progenitor cells, would they be expected to. WT C17.2 behaved as expected and did not demonstrate any significant interaction with the PLGA nanoparticles during incubation. cmSA-C17.2 showed evidence of binding to the PLGA nanoparticles as expected, but then, unexpectedly, appeared to internalize the nanoparticles. This may indicate that stably binding a nanoparticle in close proximity to the cell membrane can cause internalization in otherwise hard to transfect cells. This may suggest alternative uses for mSA genes in internalizing cargos such as DNA, nanoparticles, etc., in cells that would not normally internalize them.

\section{Conclusions}

The engineered cmSA protein behaved as designed. The protein was expressed in C17.2 cell and was able to bind biotin-labeled cargo, both small molecule and nanoparticle, and release the cargo in response to uPA. This could be used as a highly targeted delivery system, with active homing from the delivery cells and passive targeting through the protease-mediated cargo release.

Author Contributions: Conceptualization: M.T.B. and D.L.T.; research methodology: M.T.B. and S.H.B.; validation: T.B.S., M.P. and T.D.T.N.; investigation: M.T.B., T.B.S., M.P., T.D.T.N. and S.A.; resources, D.L.T. and S.H.B.; writing-original draft preparation: M.T.B. writing-editing: S.A., M.P. and S.H.B.; visualization: T.B.S.; supervision, M.T.B., S.H.B. All authors have read and agreed to the published version of the manuscript.

Funding: Stefan H. Bossmann acknowledges funding from NSF, grant 1940790 and from the University of Kansas Cancer Center.

Institutional Review Board Statement: Not applicable.

Informed Consent Statement: Not applicable.

Data Availability Statement: Not applicable.

Acknowledgments: Special thanks to the Confocal Core and Microbiology Core funded by the KSU-CVM for providing use of qPCR instruments and confocal microscope.

Conflicts of Interest: The authors declare no conflict of interest.

\section{References}

1. Barrett, A.J. Clinical trials in cytotherapy. Cytotherapy 2014, 16, 147-148. [CrossRef] [PubMed]

2. Gannon, P.O.; Harari, A.; Auger, A.; Murgues, C.; Zangiacomi, V.; Rubin, O.; Ellefsen Lavoie, K.; Guillemot, L.; Navarro Rodrigo, B.; Nguyen-Ngoc, T.; et al. Development of an optimized closed and semi-automatic protocol for Good Manufacturing Practice manufacturing of tumor-infiltrating lymphocytes in a hospital environment. Cytotherapy 2020, 22, 780-791. [CrossRef]

3. Ganta, C.; Chiyo, D.; Ayuzawa, R.; Rachakatla, R.; Pyle, M.; Andrews, G.; Weiss, M.; Tamura, M.; Troyer, D. Rat umbilical cord stem cells completely abolish rat mammary carcinomas with no evidence of metastasis or recurrence 100 days post-tumor cell inoculation. Cancer Res. 2009, 69, 1815-1820. [CrossRef] [PubMed]

4. Doi, C.; Maurya, D.K.; Pyle, M.M.; Troyer, D.; Tamura, M. Cytotherapy with naive rat umbilical cord matrix stem cells significantly attenuates growth of murine pancreatic cancer cells and increases survival in syngeneic mice. Cytotherapy 2010, 12, 408-417. [CrossRef]

5. Rachakatla, R.S.; Balivada, S.; Seo, G.M.; Myers, C.B.; Wang, H.; Samarakoon, T.N.; Dani, R.; Pyle, M.; Kroh, F.O.; Walker, B.; et al. Attenuation of mouse melanoma by A/C magnetic field after delivery of bi-magnetic nanoparticles by neural progenitor cells. Acs Nano 2010, 4, 7093-7104. [CrossRef] [PubMed]

6. Seo, G.M.; Rachakatla, R.S.; Balivada, S.; Pyle, M.; Shrestha, T.B.; Basel, M.T.; Myers, C.; Wang, H.; Tamura, M.; Bossmann, S.H.; et al. A self-contained enzyme activating prodrug cytotherapy for preclinical melanoma. Mol. Biol. Rep. 2012, 39, 157-165. [CrossRef] 
7. Basel, M.T.; Balivada, S.; Wang, H.; Shrestha, T.B.; Seo, G.M.; Pyle, M.; Abayaweera, G.; Dani, R.; Koper, O.B.; Tamura, M.; et al. Cell-delivered magnetic nanoparticles caused hyperthermia-mediated increased survival in a murine pancreatic cancer model. Int. J. Nanomed. 2012, 7, 297-306. [CrossRef]

8. Basel, M.T.; Balivada, S.; Shrestha, T.B.; Seo, G.M.; Pyle, M.M.; Tamura, M.; Bossmann, S.H.; Troyer, D.L. A cell-delivered and cell-activated SN38-dextran prodrug increases survival in a murine disseminated pancreatic cancer model. Small (Weinh. Der Bergstr. Ger.) 2012, 8, 913-920. [CrossRef]

9. Soond, S.M.; Kozhevnikova, M.V.; Zamyatnin, A.A., Jr. 'Patchiness' and basic cancer research: Unravelling the proteases. Cell Cycle (Georget. Tex.) 2019, 18, 1687-1701. [CrossRef] [PubMed]

10. Kesavardhana, S.; Malireddi, R.K.S.; Kanneganti, T.D. Caspases in Cell Death, Inflammation, and Pyroptosis. Annu. Rev. Immunol. 2020, 38, 567-595. [CrossRef]

11. Heinz, A. Elastases and elastokines: Elastin degradation and its significance in health and disease. Crit. Rev. Biochem. Mol. Biol. 2020, 55, 252-273. [CrossRef]

12. Bogenrieder, T.; Herlyn, M. Axis of evil: Molecular mechanisms of cancer metastasis. Oncogene 2003, 22, 6524-6536. [CrossRef] [PubMed]

13. Duffy, M.J. Proteases as prognostic markers in cancer. Clin. Cancer Res. Off. J. Am. Assoc. Cancer Res. 1996, 2, 613-618.

14. Johansson, N.; Ahonen, M.; Kahari, V.M. Matrix metalloproteinases in tumor invasion. Cell. Mol. Life Sci. CMLS 2000, 57, 5-15. [CrossRef]

15. Turk, B.E.; Huang, L.L.; Piro, E.T.; Cantley, L.C. Determination of protease cleavage site motifs using mixture-based oriented peptide libraries. Nat. Biotechnol. 2001, 19, 661-667. [CrossRef] [PubMed]

16. Khasigov, P.Z.; Podobed, O.V.; Gracheva, T.S.; Salbiev, K.D.; Grachev, S.V.; Berezov, T.T. Role of matrix metalloproteinases and their inhibitors in tumor invasion and metastasis. Biochem..Biokhimiia 2003, 68, 711-717. [CrossRef]

17. Duffy, M.J. Urokinase-type plasminogen activator: A potent marker of metastatic potential in human cancers. Biochem. Soc. Trans. 2002, 30, 207-210. [CrossRef] [PubMed]

18. Liu, S.; Bugge, T.H.; Leppla, S.H. Targeting of tumor cells by cell surface urokinase plasminogen activator-dependent anthrax toxin. J. Biol. Chem. 2001, 276, 17976-17984. [CrossRef] [PubMed]

19. Borgford, T. Ricin-Like Toxin Variants Comprising A Chain and B Chain Linked with a Linker for Treatment of Cancer, Viral or Parasitic Infections. U.S. Patent 6803358B1, 16 July 2004.

20. Stayton, P.S.; Freitag, S.; Klumb, L.A.; Chilkoti, A.; Chu, V.; Penzotti, J.E.; To, R.; Hyre, D.; Le Trong, I.; Lybrand, T.P.; et al. Streptavidin-biotin binding energetics. Biomol. Eng. 1999, 16, 39-44. [CrossRef]

21. Demonte, D.; Drake, E.J.; Lim, K.H.; Gulick, A.M.; Park, S. Structure-based engineering of streptavidin monomer with a reduced biotin dissociation rate. Proteins 2013, 81, 1621-1633. [CrossRef] [PubMed]

22. Lim, K.H.; Huang, H.; Pralle, A.; Park, S. Stable, high-affinity streptavidin monomer for protein labeling and monovalent biotin detection. Biotechnol. Bioeng. 2013, 110, 57-67. [CrossRef]

23. Micanovic, R.; Gerber, L.D.; Berger, J.; Kodukula, K.; Udenfriend, S. Selectivity of the cleavage/attachment site of phosphatidylinositol-glycan-anchored membrane proteins determined by site-specific mutagenesis at Asp-484 of placental alkaline phosphatase. Proc. Natl. Acad. Sci. USA 1990, 87, 157-161. [CrossRef] [PubMed]

24. Chen, X.; Zaro, J.L.; Shen, W.C. Fusion protein linkers: Property, design and functionality. Adv. Drug Deliv. Rev. 2013, 65, 1357-1369. [CrossRef]

25. Ourednik, J.; Ourednik, V.; Lynch, W.P.; Schachner, M.; Snyder, E.Y. Neural Stem Cells Display an Inherent Mechanism for Rescuing Dysfunctional Neurons. Nat. Biotechnol. 2002, 20, 1103-1110. [CrossRef]

26. Yu, K.; Liu, C.; Kim, B.G.; Lee, D.Y. Synthetic fusion protein design and applications. Biotechnol. Adv. 2015, 33, 155-164. [CrossRef]

27. Grünberg, R.; Serrano, L. Strategies for protein synthetic biology. Nucleic Acids Res. 2010, 38, 2663-2675. [CrossRef] [PubMed] 